Article

\title{
Screening of Activated Carbons for the Treatment of Highly Concentrated Phenol Solutions Using Catalytic Wet Peroxide Oxidation: The Effect of Iron Impurities on the Catalytic Activity
}

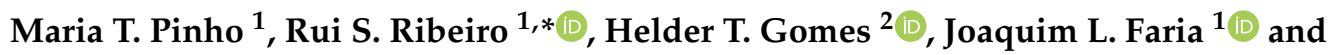 \\ Adrián M. T. Silva ${ }^{1}$ (D) \\ 1 Laboratory of Separation and Reaction Engineering-Laboratory of Catalysis and Materials (LSRE-LCM), \\ Faculdade de Engenharia, Universidade do Porto, Rua Doutor Roberto Frias, 4200-465 Porto, Portugal; \\ teresapinho847@gmail.com (M.T.P.); jlfaria@fe.up.pt (J.L.F.); adrian@fe.up.pt (A.M.T.S.) \\ 2 Centro de Investigação de Montanha (CIMO), Instituto Politécnico de Bragança, Campus de Santa Apolónia, \\ 5300-253 Bragança, Portugal; htgomes@ipb.pt \\ * Correspondence: rsribeiro@fe.up.pt
}

Received: 6 October 2020; Accepted: 10 November 2020; Published: 13 November 2020

\begin{abstract}
Activated carbons (ACs) have been used as metal supports for catalytic wet peroxide oxidation (CWPO) of organic compounds. A shortcoming is that added metals can undergo leaching, leading to catalyst deactivation and secondary contamination of the treated water. In the present study, CWPO of phenol aqueous solutions was investigated in the presence of five commercial ACs without added metals yet containing different extents of iron impurities resulting from their industrial preparation procedures (ROX 0.8, RX 3-Extra, C-Gran and PK 0.25-1 from Cabot Norit and HYDRAFFIN AS 12/450 from Degussa). Application of as-received ROX 0.8 leads to the best compromise between removals of phenol (79\%) and total organic carbon (TOC; $50 \%$ ) and iron leaching $\left(0.22 \mathrm{mg} \mathrm{L}^{-1}\right)$. In-house-modified ROX 0.8 materials, obtained by thermal treatment under inert atmosphere followed by activation under oxidative atmosphere, were also tested. The activity of ROX 0.8 oxidized at $673 \mathrm{~K}\left(\mathrm{ROXN}_{673}\right)$ was the highest among these materials $(92 \%$ and $57 \%$ of phenol and TOC removals, respectively) and with iron leaching $\left(0.67 \mathrm{mg} \mathrm{L}^{-1}\right)$ well below the limits established by European regulations for discharge of treated waters. This enhanced performance was mainly explained by the more developed porous structure and higher specific surface area $\left(S_{\mathrm{BET}}\right)$ of $R O \mathrm{RN}_{673}$, thus promoting better accessibility to iron impurities, which act as active sites for CWPO at the surface of the catalyst.
\end{abstract}

Keywords: advanced oxidation processes (AOPs); CWPO; heterogeneous Fenton process; carbon materials; catalytic activity; wastewater treatment; phenol; environmental protection; water

\section{Introduction}

Activated carbons (ACs) are suitable materials for an extensive range of heterogeneous catalysis applications, either as supports or as catalysts themselves. The performance of these materials is greatly influenced by their surface area and porous structure [1,2], as well as by the specific active sites on its surface $[3,4]$, which play a dominant role in the adsorption and oxidation of contaminants. Other exciting characteristics include their cost (relatively cheap), resistance to heat and radiation, good mechanical strength and stability in acidic/basic solutions [5]. The surface chemistry of ACs is characterized by different oxygen functional groups, such as carboxylic acids, lactones, phenols, 
carbonyls/quinones and anhydrides. These oxygen groups can be inset in or withdrawn from the surface of the materials by liquid- and gas-phase thermal treatments [6].

ACs have been widely explored as supports for metal catalysts (mainly iron) to be applied in the removal of organic compounds by catalytic wet peroxide oxidation (CWPO) $[7,8]$. However, the main drawback of metal-supported catalysts is the possibility of metal leaching from the support to the solution, thereby causing secondary contamination of the treated water and compromising catalyst stability $[7,8]$. As ACs without added metals were found to promote the formation of hydroxyl radicals $\left(\mathrm{HO}^{\bullet}\right)$ by decomposition of hydrogen peroxide $\left(\mathrm{H}_{2} \mathrm{O}_{2}\right)$, they started to be regarded as alternatives to metal-supported catalysts in CWPO processes [7]. In a previous publication, our group proposed a mechanism for the decomposition of $\mathrm{H}_{2} \mathrm{O}_{2}$ when metal-free carbon materials are used as catalysts, based on experimental results and other findings reported in the literature [7]. It involves the participation of reduced active sites [AS], i.e., electron donor sites existing at the carbon surface (e.g., basic oxygen-containing groups, such as chromene and pyrone, basic nitrogen-containing functionalities or delocalized $\pi$-electrons at the basal carbon planes) and oxidized active sites [ $\left.\mathrm{AS}^{+}\right]$, i.e., electron acceptor sites, according to the catalytic surface reactions described by Equations (1)-(3). These radicals are strong oxidants and highly unstable active species, reacting with most organic compounds $[9,10]$.

$$
\begin{gathered}
{\left[\mathrm{H}_{2} \mathrm{O}_{2}+\mathrm{AS}\right] \rightarrow \mathrm{HO}^{\bullet}+\mathrm{OH}^{-}+\left[\mathrm{AS}^{+}\right]} \\
{\left[\mathrm{H}_{2} \mathrm{O}_{2}+\mathrm{AS}^{+}\right] \rightarrow\left[\mathrm{HOO}^{\bullet}+\mathrm{H}^{+}+\mathrm{AS}\right]} \\
{\left[\mathrm{HOO}^{\bullet}+\mathrm{H}^{+}+\mathrm{AS}\right] \rightarrow \mathrm{H}_{2} \mathrm{O}+\left[\mathrm{O}^{\bullet}+\mathrm{AS}^{+}\right]}
\end{gathered}
$$

Most CWPO applications typically deal with pollutants present in water at low concentrations (up to $0.1 \mathrm{~g} \mathrm{~L}^{-1}$ ) $[7,8]$. Nevertheless, studies performed with metal-free carbon-based catalysts show that higher $\mathrm{H}_{2} \mathrm{O}_{2}$ consumption efficiencies (close to $100 \%$ ) can be obtained when operating at higher pollutant loads (up to $5 \mathrm{~g} \mathrm{~L}^{-1}$ ) under a process intensification approach. These studies include distinct materials such as AC [11], carbon black [12] and carbon nanotubes [13]. The enhanced efficiency of $\mathrm{H}_{2} \mathrm{O}_{2}$ consumption has been ascribed to the increased coverage of the carbon surface by organic molecules (i.e., increased adsorptive interactions) $[14,15]$. This approach also allows expanding the range of industrial wastewater treatment applications of CWPO, as demonstrated in our previous publication on the treatment of a highly polluted liquid effluent from a mechanical biological treatment plant for municipal solid waste [16]. Bearing this in mind, the main objective of the present work is to study the performance of several ACs without added metals in CWPO using a high pollutant/AC mass ratio to maximize the efficiency of $\mathrm{H}_{2} \mathrm{O}_{2}$ consumption. For that purpose, five different commercial ACs without added metals were tested as catalysts for CWPO, considering highly concentrated phenol solutions $\left(4.5 \mathrm{~g} \mathrm{~L}^{-1}\right)$ as a model system. A systematic work was performed to understand the role of different characteristics of ACs (texture, presence of iron impurities and surface chemistry) in their performance as catalysts. Moreover, the sample Norit ROX 0.8 (ROX)—an AC widely employed in water treatment $[1,14,17]$ - was subjected to heat treatment using different (inert and oxidative) atmospheres and temperatures (from 473 to $673 \mathrm{~K}$ ).

\section{Results and Discussion}

\subsection{Characterization of the AC Samples}

The textural properties and $\mathrm{pH}$ at the point of zero charge $\left(\mathrm{pH}_{\mathrm{PZC}}\right)$ of the ACs under study (cf. Section 3.2) are given in Table 1. As observed, all the ACs are microporous materials with ratios between microporous volume $\left(V_{\text {mic }}\right)$ and total pore volume $\left(V_{\text {Total }}\right)$, i.e., $V_{\text {mic }} / V_{\text {Total }}$, higher than 0.5 and specific surface area $\left(S_{\mathrm{BET}}\right)$ values above $660 \mathrm{~m}^{2} \mathrm{~g}^{-1}$. RX3 presents the highest $S_{\mathrm{BET}}$, followed by AS12 $\approx$ C-GRAN $>$ ROX $>>$ PK0.25. Most of the samples reveal a nearly neutral character, as demonstrated by $\mathrm{pH}_{\mathrm{PZC}}$ values in the range 6.3-7.8. The exception is C-GRAN, which possesses a markedly acidic nature $\left(\mathrm{pH}_{\mathrm{PZC}}<3\right)$. 
Table 1. Specific surface area $\left(S_{\mathrm{BET}}\right)$, total pore volume $\left(V_{\text {Total }}\right)$, microporous volume $\left(V_{\text {mic }}\right)$ and $\mathrm{pH}$ PZC of the AC samples.

\begin{tabular}{cccccc}
\hline Material & $\begin{array}{c}S_{\mathbf{B E T}} / \\
\mathbf{m}^{\mathbf{2}} \mathbf{g}^{\mathbf{- 1}}\end{array}$ & $\begin{array}{c}V_{\text {total }} / \\
\mathbf{c m}^{\mathbf{3}} \mathbf{g}^{\mathbf{- 1}}\end{array}$ & $\begin{array}{c}V_{\text {mic }} / \\
\mathbf{c m}^{\mathbf{3}} \mathbf{g}^{\mathbf{- 1}}\end{array}$ & $\boldsymbol{V}_{\text {mic }} / V_{\text {total }}$ & $\mathbf{p H} \mathbf{H Z C}_{\mathbf{P Z C}}$ \\
\hline ROX & 1121 & 0.681 & 0.466 & 0.685 & 6.3 \\
RX3 & 1352 & 0.663 & 0.588 & 0.886 & 6.8 \\
C-GRAN & 1273 & 0.918 & 0.499 & 0.543 & 2.8 \\
PK0.25 & 661 & 0.424 & 0.271 & 0.640 & 7.8 \\
AS12 & 1276 & 0.594 & 0.525 & 0.883 & 7.4 \\
\hline ROXN & 1100 & 0.649 & 0.463 & 0.713 & 8.2 \\
ROXN $_{473}$ & 1063 & 0.627 & 0.436 & 0.695 & 7.4 \\
ROXN $_{573}$ & 1065 & 0.619 & 0.441 & 0.712 & 7.2 \\
ROXN $_{673}$ & 1149 & 0.730 & 0.528 & 0.723 & 4.1 \\
\hline
\end{tabular}

Regarding the in-house-modified materials, the thermal treatments have a modest effect on the surface area and porosity of ROX (cf. Table 1). This is particularly clear in ROXN (i.e., ROX thermally treated under $\mathrm{N}_{2}$ atmosphere at $1073 \mathrm{~K}$ ), which possess an $S_{\text {BET }}$ of $1100 \mathrm{~m}^{2} \mathrm{~g}^{-1}$, representing a $<2 \%$ variation when compared to that of bare ROX $\left(1121 \mathrm{~m}^{2} \mathrm{~g}^{-1}\right)$. Regarding the materials thermally treated under oxidative atmosphere (air) at 473,573 and $673 \mathrm{~K}$, only that prepared at $673 \mathrm{~K}\left(\mathrm{ROXN}_{673}\right)$ possesses a more developed porous structure $\left(V_{\text {total }}=0.730 \mathrm{~cm}^{3} \mathrm{~g}^{-1}\right)$ and $S_{\text {BET }}$ higher than that of bare ROX. The surface chemistry of ROX is affected by the thermal treatment under the $\mathrm{N}_{2}$ atmosphere at $1073 \mathrm{~K}$, as shown by the $\mathrm{pH}_{\mathrm{PZC}}>8$ of ROXN, which demonstrates that the thermal treatment selectively removes the more acidic groups from the carbon surface $[18,19]$. This effect is also evidenced by the decrease of the oxygen content of the materials, namely from 7.7 to $3.0 \mathrm{wt} \%$ in ROX and ROXN, respectively (cf. Table 2). On the contrary, the $\mathrm{pH}_{\mathrm{PZC}}$ gradually decreases (down to 4.1) as the oxidizing treatment temperature with air increases. This can be explained by the increased incorporation of acidic oxygen-containing surface functionalities [20,21], as also confirmed by the oxygen contents given in Table 2. Specifically, $\mathrm{ROXN}_{673}$ possesses an oxygen content of $22.1 \mathrm{wt} \%$, a value far superior to that of bare ROX (7.7 wt \%).

Table 2. Amounts of $\mathrm{CO}$ and $\mathrm{CO}_{2}$ released by TPD, $\mathrm{CO} / \mathrm{CO}_{2}$ ratio, percentage of oxygen obtained from the analysis of the temperature-programmed desorption (TPD) spectra (assuming that all the surface oxygen is released as $\mathrm{CO}$ and $\mathrm{CO}_{2}$ ) and iron content of the activated carbon (AC) samples.

\begin{tabular}{|c|c|c|c|c|c|}
\hline Material & $\begin{array}{c}{[\mathrm{CO}] /} \\
\mu \mathrm{mol} \mathrm{g}\end{array}$ & $\begin{array}{c}{\left[\mathrm{CO}_{2}\right] /} \\
\mu \mathrm{mol} \mathrm{g}^{-1}\end{array}$ & $\mathrm{CO} / \mathrm{CO}_{2}$ & $\begin{array}{c}\mathrm{O} / \\
\text { wt } \%\end{array}$ & $\begin{array}{c}\text { [Iron]/ } \\
\text { wt \% }\end{array}$ \\
\hline ROX & 2058 & 1364 & 1.5 & 7.7 & 0.04 \\
\hline RX3 & 816 & 735 & 1.1 & 3.7 & 0.08 \\
\hline C-GRAN & 3128 & 7736 & 0.4 & 29.8 & 0.04 \\
\hline PK0.25 & 516 & 414 & 1.2 & 2.2 & 0.17 \\
\hline AS12 & 2946 & 2394 & 1.2 & 12.4 & 0.29 \\
\hline ROXN & 657 & 606 & 1.1 & 3.0 & 0.06 \\
\hline $\mathrm{ROXN}_{473}$ & 935 & 472 & 2.0 & 3.0 & 0.10 \\
\hline $\mathrm{ROXN}_{573}$ & 1995 & 795 & 2.5 & 5.7 & 0.04 \\
\hline $\mathrm{ROXN}_{673}$ & 1303 & 6266 & 0.2 & 22.1 & 0.06 \\
\hline
\end{tabular}

Temperature programmed desorption (TPD) is a technique especially suitable for the determination of the type and amount of oxygenated groups on the surface of carbon materials such as ACs. These groups decompose with temperature, being released as $\mathrm{CO}$ and $\mathrm{CO}_{2}$. Carboxylic anhydrides, phenols, carbonyls and quinones and basic surface groups, such as pyrones and chromenes, are dismissed as $\mathrm{CO}$, while carboxylic acids, lactones and carboxylic anhydrides are released as 
$\mathrm{CO}_{2}$. More information regarding the determination and quantification of the several decomposing surface groups may be found elsewhere $[19,22,23]$.

The results obtained by TPD for the commercial and the thermally modified ROX materials are given in Table 2. As observed, $\mathrm{PK} 0.25$ presents the lowest amount of functional groups released as $\mathrm{CO}$ and $\mathrm{CO}_{2}$ among the commercial ACs, while C-GRAN presents the highest quantity. C-GRAN also delivers the lowest $\mathrm{CO} / \mathrm{CO}_{2}$ ratio (0.4) since the amount of surface groups released as $\mathrm{CO}$ is lower than those released as $\mathrm{CO}_{2}$. This observation suggests that C-GRAN possesses higher amounts of acidic oxygen-containing surface groups, which agrees with the $\mathrm{pH}_{\mathrm{PZC}}$ results previously discussed (cf. Table 1).

Among the thermally modified ROX materials, $\mathrm{ROXN}_{673}$ presents the highest quantity of oxygen-containing functional groups released as $\mathrm{CO}_{2}$ and the lowest $\mathrm{CO} / \mathrm{CO}_{2}$ ratio (0.2), which is in accordance with the acidic character shown in Table 1. ROXN and $\mathrm{ROXN}_{573}$ present the lowest and highest amount of surface groups released as $\mathrm{CO}$, respectively and $\mathrm{ROXN}_{473}$, the lowest amount of $\mathrm{CO}_{2}$ releasing groups.

The amount of iron impurities resulting from the commercial procedures used to prepare the ACs under study was determined by atomic absorption (cf. Section 3.3). As observed, AS12 presents the highest amount of iron species in its structure, followed by PK0.25 >> RX3 >C-GRAN $=$ ROX (cf. Table 2). In modified ROX materials, the load of iron species is similar.

\subsection{Adsorption Experiments}

Adsorption experiments were performed to compare the removals of phenol by adsorption with the removals by CWPO, thus understanding the influence of adsorption on the mechanism of pollutant removal. The results obtained in adsorption experiments performed during $24 \mathrm{~h}$ with the commercial AC samples, under the operating conditions described in Section 3.4, are given in Figure 1 and Table 3. As observed, phenol removals do not exceed $22 \%$ of its initial content, regardless of the commercial AC employed as adsorbent. ROX presents the highest adsorption capacity, followed by RX3 > AS12 > C-GRAN > PK0.25. Analyzing together the results obtained in the adsorption runs with the textural characteristics of the samples (cf. Table 1), it is concluded that the adsorption of phenol is not proportional to $S_{\mathrm{BET}}$. For instance, although the $S_{\mathrm{BET}}$ of RX3 is higher than that of ROX, the latter promoted higher phenol adsorption. This observation shows that the adsorption mechanism is not governed only by the available surface area of the carbon materials but is also influenced by other factors such as surface chemistry [24,25].

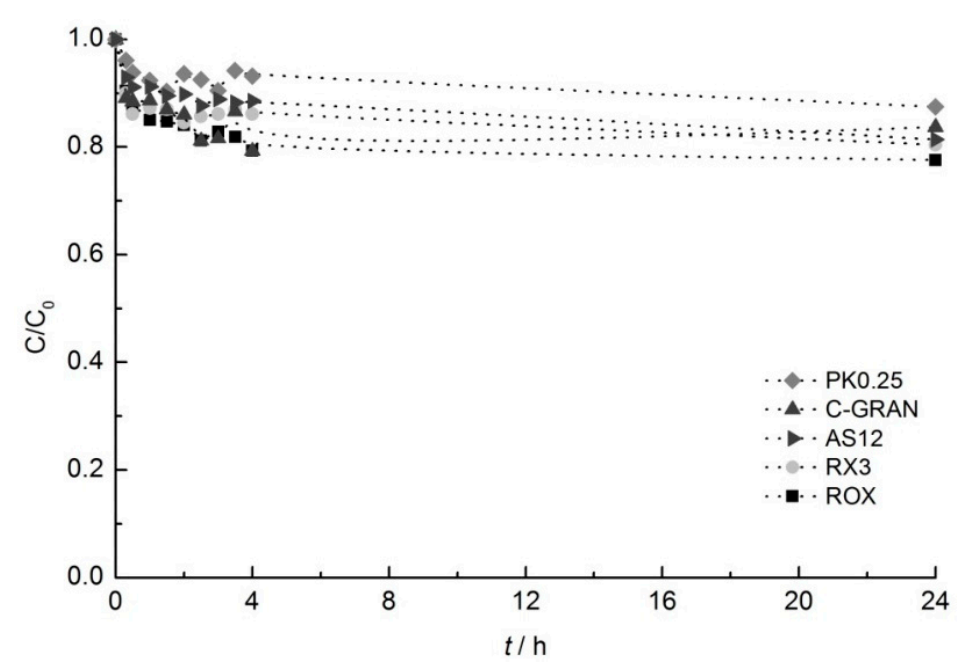

Figure 1. Phenol normalized concentration obtained as a function of time in adsorption runs performed with the commercial AC samples. Experiments performed with [phenol] $=4.5 \mathrm{~g} \mathrm{~L}^{-1}$, [adsorbent] $=2.5 \mathrm{~g} \mathrm{~L}^{-1}, T=353 \mathrm{~K}$ and $\mathrm{pH}=3.5$. 
Table 3. Removals of phenol ( $\left.X_{\text {Phenol }}\right)$ obtained after $24 \mathrm{~h}$ in adsorption and catalytic wet peroxide oxidation (CWPO) runs performed with the AC samples, with [phenol] $=4.5 \mathrm{~g} \mathrm{~L}^{-1}$, [adsorbent/catalyst] $=2.5 \mathrm{~g} \mathrm{~L}^{-1}, T=353 \mathrm{~K}$ and $\mathrm{pH}=3.5$.

\begin{tabular}{ccccc}
\hline \multirow{2}{*}{ Material } & \multicolumn{2}{c}{$\boldsymbol{X}_{\text {Phenol }} / \mathbf{\%}$} & \multicolumn{2}{c}{$\boldsymbol{X}_{\text {Phenol }} / \mathbf{m g ~ g}^{-\mathbf{1}}$} \\
\cline { 2 - 5 } & Adsorption & CWPO & Adsorption & CWPO \\
\hline ROX & 22 & 79 & 396 & 1422 \\
RX3 & 20 & 93 & 360 & 1674 \\
C-GRAN & 16 & 85 & 288 & 1530 \\
PK0.25 & 12 & 100 & 216 & 1800 \\
AS12 & 19 & 100 & 342 & 1800 \\
\hline ROXN & 20 & 77 & 360 & 1386 \\
ROXN $_{473}$ & 19 & 79 & 342 & 1422 \\
ROXN $_{573}$ & 27 & 82 & 486 & 1476 \\
ROXN $_{673}$ & 14 & 92 & 252 & 1656 \\
\hline
\end{tabular}

\subsection{CWPO Experiments}

The results obtained in CWPO runs performed during $24 \mathrm{~h}$ with the commercial AC samples, under the operating conditions described in Section 3.4, are given in Figure 2 and Table 3. Non-catalytic removals are also given in Figure 2 for comparison. As observed, phenol removals over $75 \%$ of its initial content are obtained by CWPO, regardless of the commercial AC employed as catalyst. These removals are far superior to those obtained by adsorption (cf. Figure 1) and in the absence of a catalyst (cf. Figure 2), allowing to conclude that all the ACs under study are active catalysts for CWPO. The highest removals of phenol by CWPO were obtained with AS12 and PK0.25 (i.e., 100\% after $24 \mathrm{~h}$ ), followed by RX3 > C-GRAN > ROX. A similar trend was obtained regarding total organic carbon (TOC) conversion $\left(X_{\mathrm{TOC}}\right)$, except that in this case, C-GRAN performed worse than ROX (cf. Figure 3). These results may be explained by the different extents of iron impurities resulting from the preparation procedures of the commercial ACs. As previously discussed, AS12 and PK0.25 present the highest iron content among the catalysts (cf. Table 2). Consequently, the CWPO results may be influenced by iron in these catalysts, justifying the best performances revealed by AS12 and PK0.25. To provide further insights on the influence of iron impurities, the concentration of iron leaching into the treated water, as determined at the end of the CWPO runs, is also given in Figure 3. The results confirmed that the highest concentration of iron leaching is obtained with AS12 $\left(5.2 \mathrm{mg} \mathrm{L}^{-1}\right)$, followed by PK0.25 >> RX3 > C-GRAN $\approx$ ROX, precisely the order of the iron content in each AC. Specifically, the amount of iron leached from AS12 during $24 \mathrm{~h}$ corresponds to $71 \%$ of its initial content (cf. Table 2), whereas the loss of iron from ROX under the same conditions amounts only to $22 \%$. It is well known that $\mathrm{HO}^{\bullet}$ radicals are formed from the decomposition of $\mathrm{H}_{2} \mathrm{O}_{2}$ in the presence of iron species [8]. Thus, it is expected that the catalytic reactions should occur both at the catalyst surface (cf. Equations (1)-(3)) and in solution [8]. These observations highlight the influence of ash impurities, like iron, in the catalytic activity of carbon materials. Moreover, the leaching levels obtained with AS12 and PK0.25 are above the concentration limits allowed by EU Directives for the discharge of treated water into natural receiving water bodies $\left(2 \mathrm{mg} \mathrm{L}^{-1}\right)$. Therefore, other materials apparently presenting lower catalytic activity, but leading to significantly lower amounts of iron leaching (e.g., RX3, C-GRAN and ROX), may be found more suitable for CWPO. 


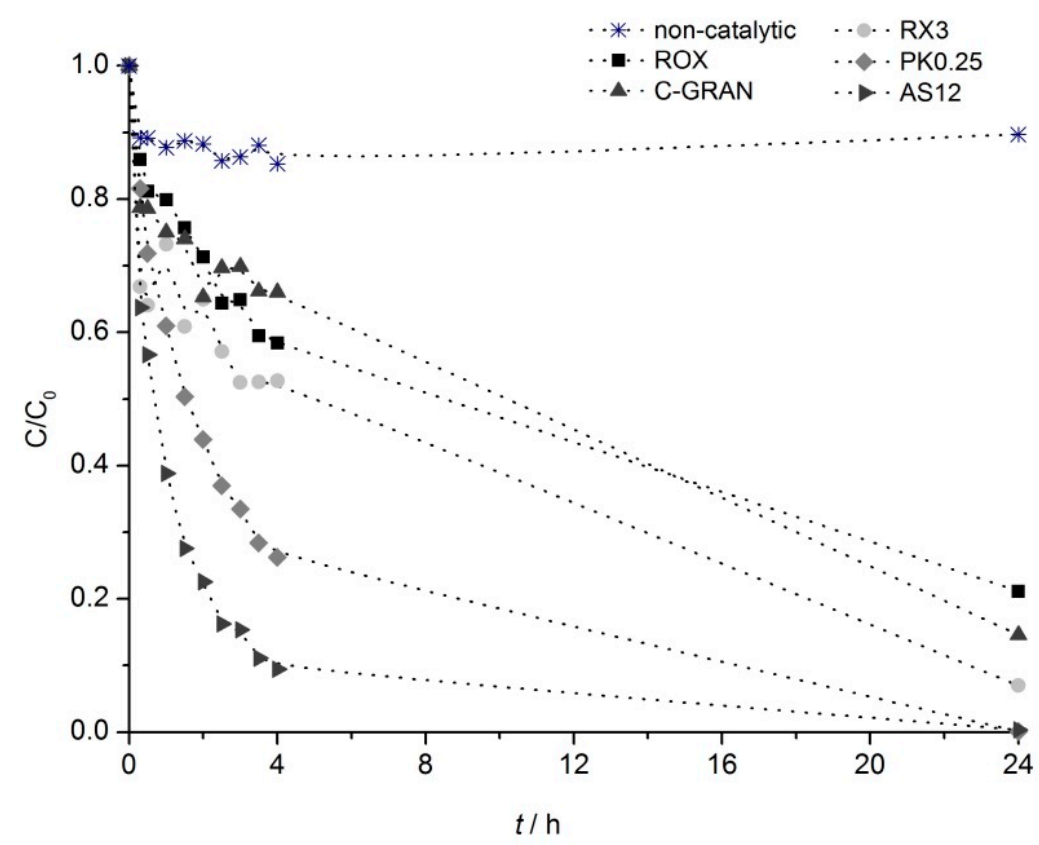

Figure 2. Phenol normalized concentration obtained as a function of time in CWPO runs performed with the commercial AC samples. Experiments performed with [phenol] $=4.5 \mathrm{~g} \mathrm{~L}^{-1}$, [catalyst] $=2.5 \mathrm{~g} \mathrm{~L}^{-1}$, $T=353 \mathrm{~K}, \mathrm{pH}=3.5$ and $\left[\mathrm{H}_{2} \mathrm{O}_{2}\right]=25 \mathrm{~g} \mathrm{~L}^{-1}$ (stoichiometric amount).

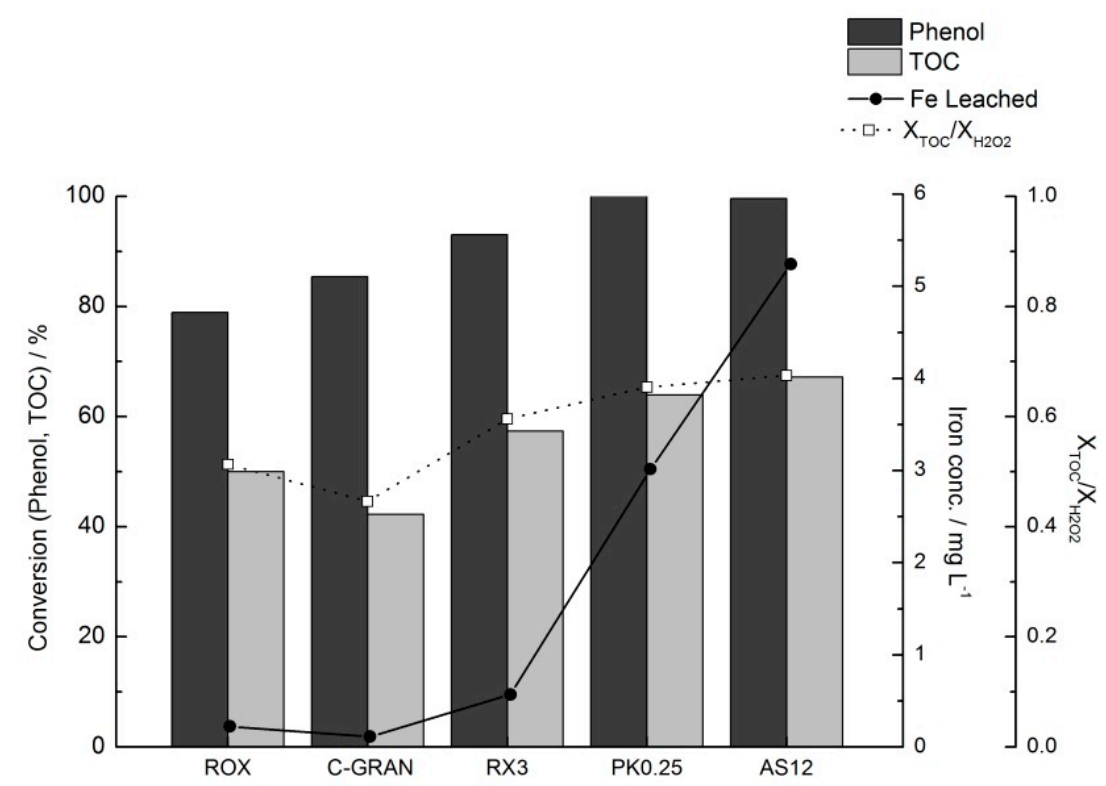

Figure 3. Conversions of phenol and total organic carbon (TOC) (respectively dark and light bars/left axis) and concentration of iron leached into solution, and $\mathrm{X}_{\mathrm{TOC}} / \mathrm{X}_{\mathrm{H}_{2} \mathrm{O}_{2}}$ (respectively squares and circles/right axis), obtained after $24 \mathrm{~h}$ in CWPO runs performed under the conditions given in Figure 2.

Regarding mineralization levels, TOC conversions obtained with the commercial ACs are always lower than phenol removals (cf. Figure 3). These results suggest the formation of recalcitrant byproducts during the reaction, probably through the oxidation of phenol into catechol, resorcinol, hydroquinone and $p$-benzoquinone and several low molecular weight acids, as shown in previous studies dealing with the application of ACs [14] and carbon nanotubes [13] in CWPO.

During CWPO, pollutant and $\mathrm{H}_{2} \mathrm{O}_{2}$ molecules compete for the available active sites at the surface of the solid catalyst. This has been demonstrated in a previous work of our group, in which it was shown that $\mathrm{H}_{2} \mathrm{O}_{2}$ decomposition during CWPO increases significantly in the absence of pollutant 
molecules [26]. Nevertheless, decomposition of $\mathrm{H}_{2} \mathrm{O}_{2}$ may be associated with higher yields of $\mathrm{HO}^{\bullet}$ radicals and, consequently, to higher TOC conversions. However, several parasitic reactions may occur, leading to inefficient use of those radicals [7,8]. Bearing this in mind, the ratio between TOC and $\mathrm{H}_{2} \mathrm{O}_{2}$ conversions $\left(X_{\mathrm{TOC}} / \mathrm{X}_{\mathrm{H} 2 \mathrm{O} 2}\right)$ was used to study the efficiency of $\mathrm{H}_{2} \mathrm{O}_{2}$ consumption. Indeed, this has been the most common strategy to quantify the overall efficiency of CWPO [14,27]. As observed, $X_{\mathrm{TOC}} / X_{\mathrm{H} 2 \mathrm{O} 2}$ values above 0.5 are obtained with all catalysts, except for C-GRAN. These results confirm the high efficiency of $\mathrm{H}_{2} \mathrm{O}_{2}$ consumption when CWPO is operated under a process intensification approach (in this case, by considering a phenol/AC mass ratio of 1.8). Moreover, this approach also allows obtaining high pollutant mass removals, in the range $1422-1800 \mathrm{mg} \mathrm{g}^{-1}$ (cf. Table 3).

\subsubsection{Influence of Surface Chemistry}

Among the five commercial AC samples employed in CWPO, ROX presented the best compromise between catalytic performance (significant conversions of both phenol and TOC, i.e., 79 and 50\%, respectively) and iron leaching $\left(0.22 \mathrm{mg} \mathrm{L}^{-1}\right)$, as well as an $X_{\mathrm{TOC}} / \mathrm{X}_{\mathrm{H} 2 \mathrm{O} 2}$ above 0.5 (cf. Figure 3). Therefore, ROX was selected for additional studies on the influence of surface chemistry in the CWPO of highly concentrated phenol solutions. Accordingly, ROX was treated under a nitrogen atmosphere at $1073 \mathrm{~K}$, resulting in the ROXN materials. ROXN was then thermally activated under an oxidative atmosphere at different temperatures (from 473 to $673 \mathrm{~K}$ ), as described in Section 3.2. The removals of phenol obtained in adsorption and CWPO experiments performed with these materials are given in Figure $4 \mathrm{a}, \mathrm{b}$ and Table 3 . As observed, phenol removals in the range $14-27 \%$ are obtained after $24 \mathrm{~h}$ of adsorption on the thermally modified samples, a value quite similar to that obtained when bare ROX is used as adsorbent (22\%; cf. Table 3). Therefore, it is concluded that thermal treatments have a negligible effect on the adsorption capacity of the AC samples.

On the contrary, the activity in CWPO is favored upon thermal activation of ROX under an air atmosphere at $673 \mathrm{~K}$. The highest phenol removal is obtained when $\mathrm{ROXN}_{673}$ is employed in CWPO (92\%), which represents a performance superior to that obtained with ROX (79\%). In contrast, the performances of ROXN, ROXN 473 and $\mathrm{ROXN}_{573}$ are similar to those obtained with ROX (cf. Figure $4 \mathrm{~b}$ and Table 3). TOC conversions obtained under these conditions are in the range $50-60 \%$, the application of the thermally modified ROX materials leading to slightly higher mineralization levels (cf. Figure 5).

As determined at the end of the CWPO runs, the concentration of iron leached into the treated water is also given in Figure 5. It is observed that the highest amount of iron leaching is obtained with ROXN$_{673}$, which in part may explain its superior performance in CWPO since the higher amount of dissolved iron species may lead to higher decomposition of $\mathrm{H}_{2} \mathrm{O}_{2}$ into $\mathrm{HO} \mathrm{O}^{\bullet}$ radicals. As discussed above, phenol oxidation can occur at the catalyst surface (heterogeneous reaction) and in the liquid phase (homogenous reaction). Moreover, the more developed porous structure and higher $S_{\mathrm{BET}}$ of $\mathrm{ROXN}_{673}$ (cf. Table 1) can also promote better accessibility to iron active sites at the surface of the catalyst, thus enhancing $\mathrm{H}_{2} \mathrm{O}_{2}$ decomposition. Overall, the question of the extent of homogeneous and/or heterogeneous contributions of solid catalysts in liquid-phase reactions has been under debate for a long time [28]. Further insights on this question will be provided in Section 2.3.3. Nevertheless, the efficiency of $\mathrm{H}_{2} \mathrm{O}_{2}$ consumption (ratio $X_{\mathrm{TOC}} / \mathrm{X}_{\mathrm{H}_{2} \mathrm{O}_{2}}$ ) is above 0.5 in all CWPO runs, evidencing that, although it is not fully used in the mineralization process, $\mathrm{H}_{2} \mathrm{O}_{2}$ is consumed with relatively high efficiency. 


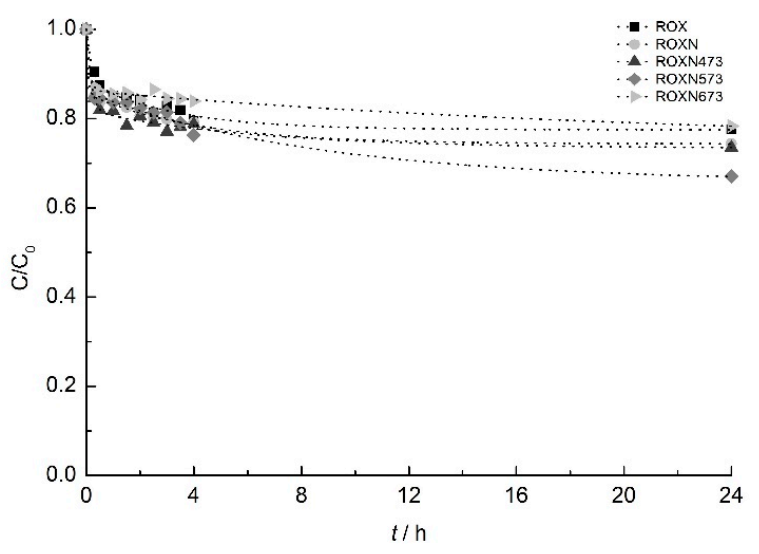

(a)

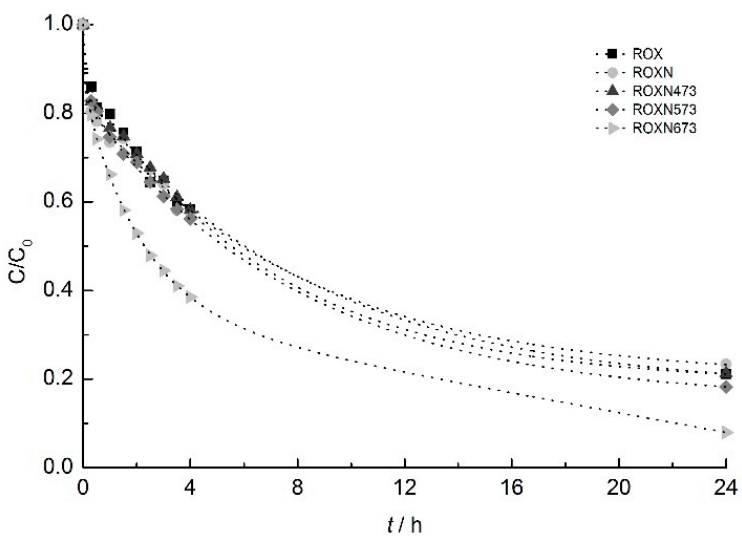

(b)

Figure 4. Phenol normalized concentration obtained as a function of time in (a) adsorption and (b) CWPO runs performed with thermally modified ROX samples. Experiments performed with [phenol] $=4.5 \mathrm{~g} \mathrm{~L}^{-1}$, [adsorbent/catalyst] $=2.5 \mathrm{~g} \mathrm{~L}^{-1}, T=353 \mathrm{~K}, \mathrm{pH}=3.5$ and, in CWPO runs, $\left[\mathrm{H}_{2} \mathrm{O}_{2}\right]=25 \mathrm{~g} \mathrm{~L}^{-1}$ (stoichiometric amount).

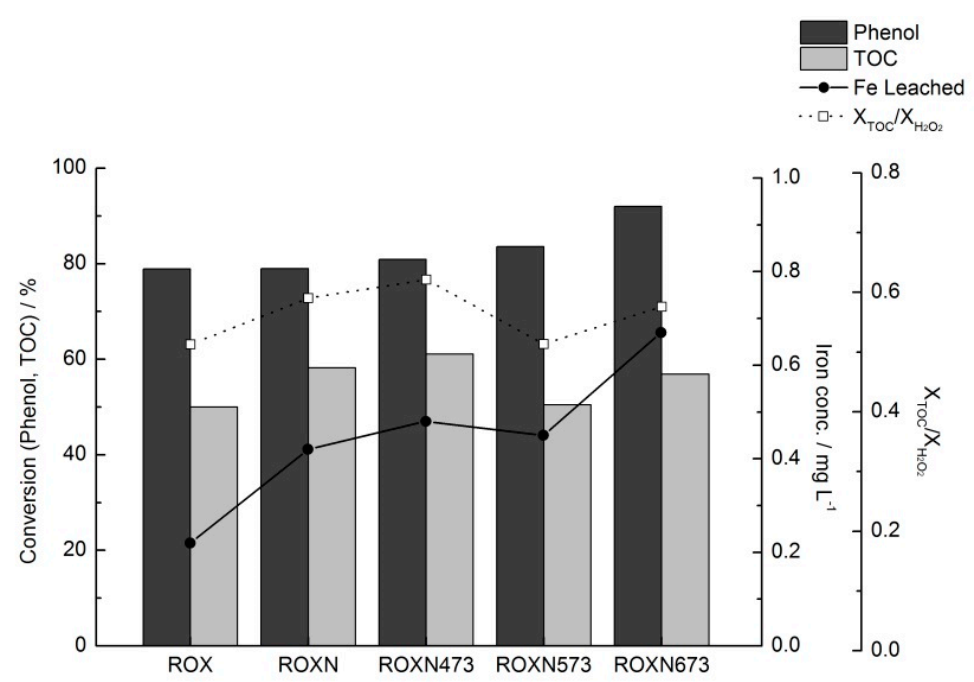

Figure 5. Conversions of phenol and TOC (respectively dark and light bars/left axis) and concentration of iron leached into solution and $\mathrm{X}_{\mathrm{TOC}} / \mathrm{X}_{\mathrm{H}_{2} \mathrm{O}_{2}}$ (respectively squares and circles/right axis), obtained after $24 \mathrm{~h}$ in CWPO runs performed under the conditions given in Figure 2. 


\subsubsection{Reaction Intermediates}

A detailed reaction mechanism for the CWPO of phenol in the presence of $\mathrm{AC}$, involving the formation of aromatic intermediates (catechol, resorcinol, hydroquinone and $p$-benzoquinone) and low molecular weight carboxylic acids (maleic, malonic, acetic, oxalic and formic acid), was proposed elsewhere [14]. The authors demonstrated the ability of $\mathrm{HO}^{\bullet}$ radicals to attack the phenol molecule in meta, ortho and para positions, leading to the formation of catechol, resorcinol and hydroquinone, respectively. Hydroquinone is then easily oxidized in solution to $p$-benzoquinone. Further attacks on the aromatic intermediates will eventually lead to ring-opening yielding carboxylic acids [14]. The formation of the proposed aromatic intermediate compounds was confirmed in our previous study on applying carbon nanotubes without added metals in the CWPO of phenol [13].

The formation of aromatic intermediates resulting from the CWPO of phenol when the treatment process is performed under the operating conditions considered in this study (i.e., considering a phenol/ $\mathrm{ROXN}_{673}$ mass ratio of 1.8) was also studied. Catechol, resorcinol, hydroquinone and $p$-benzoquinone were all detected as expected (cf. Figure 6). After a stiff increase within the first 1-2 h, the concentrations of aromatic intermediates gradually decrease. These results confirm that most of the aromatic intermediates resulting from phenol oxidation are effectively removed from solution (as inferred from a TOC conversion of almost $60 \%$ after 24 h; cf. Figure 5), possibly yielding low molecular weight carboxylic acids. Moreover, the solution $\mathrm{pH}$ was measured at the end of the CWPO run, decreasing from 3.5 to 2.2. This observation also suggests the formation of carboxylic acids during the oxidation process.

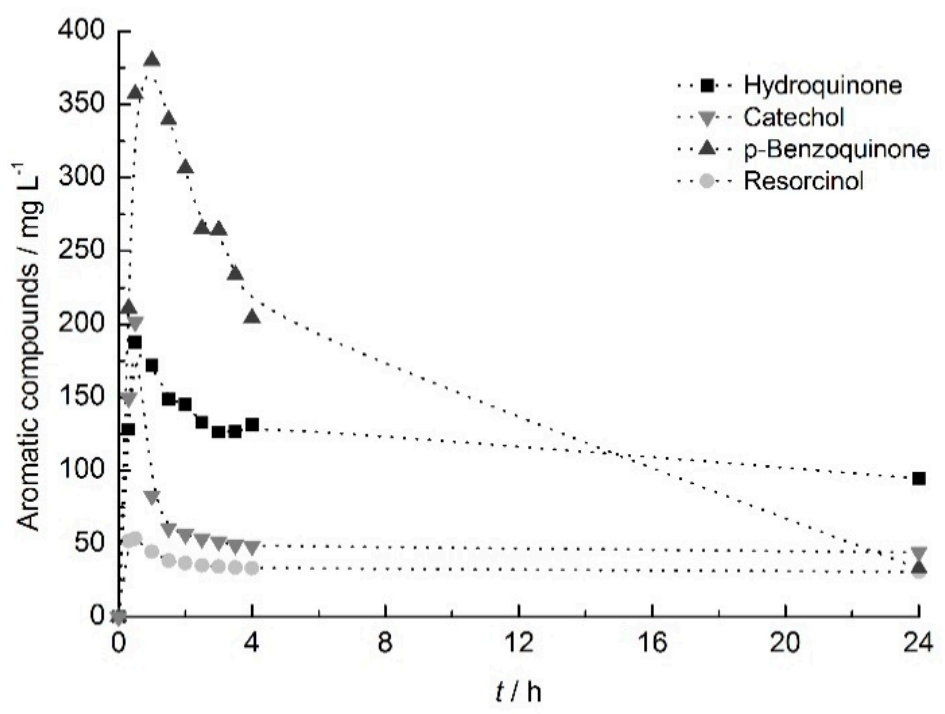

Figure 6. Evolution of aromatic intermediates of phenol oxidation when using $\mathrm{ROXN}_{673}$ in the CWPO process developed under the conditions given in Figure 2.

\subsubsection{Catalyst Stability and Reusability Studies}

The stability of ROXN 673 was studied in a series of three CWPO runs with consecutive catalyst reuse. After each CWPO run, the catalyst was recovered by filtration, washed, dried at room temperature for $12 \mathrm{~h}$ and $393 \mathrm{~K}$ for $3 \mathrm{~h}$ and reused with fresh phenol solutions. The corresponding results are given in Figure 7. As observed, both phenol and TOC conversions obtained after $24 \mathrm{~h}$ of reaction decrease from the first to the second cycle. This decrease can be explained by the absence of adsorption contribution in the second cycle. Indeed, the decrease observed regarding phenol conversion from the first to the second cycle (cf. Figure 7) resembles the phenol removal obtained by adsorption on $\mathrm{ROXN}_{673}$ (ca. $20 \%$; cf. Figure 4 a). This hypothesis is also suggested by the negligible decrease of both phenol and TOC conversions obtained from the second to third cycles. 


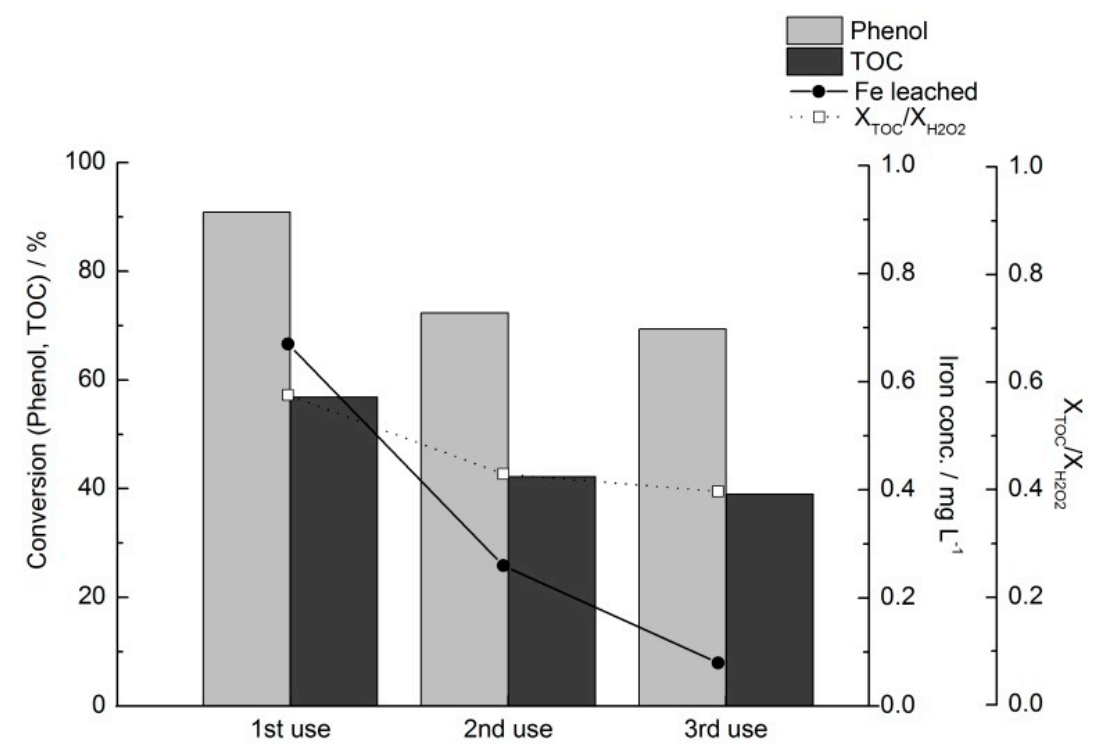

Figure 7. Conversions of phenol and TOC (respectively dark and light bars/left axis) and concentration of iron leached into solution and $X_{\mathrm{TOC}} / \mathrm{X}_{\mathrm{H}_{2} \mathrm{O}_{2}}$ (respectively squares and circles/right axis), obtained after $24 \mathrm{~h}$ in a series of three CWPO runs performed with consecutive reuse of $\mathrm{ROXN}_{673}$ under the conditions given in Figure 2.

Nevertheless, it should be noted that the concentration of iron leached into solution decreases ca. three-fold from the first to the second CWPO run (cf. Figure 7), suggesting that the oxidation process may occur not only by heterogeneous catalysts at the surface of $\mathrm{ROXN}_{673}$ but also through homogeneous catalysis promoted by iron species transferred to the solution. Specifically, the amount of iron leached from $\mathrm{ROXN}_{673}$ during the first CWPO cycle corresponds to $45 \%$ of its initial content (cf. Table 2), whereas the loss of iron during the second cycle amounts to $17 \%$. However, while iron leaching decreases again ca. three-fold from the second to the third cycle, the performance of CWPO is kept. In this case, the loss of iron from $\mathrm{ROXN}_{673}$ during the third cycle amounts only to $5 \%$ of its initial content. Therefore, it can be concluded that the decomposition of $\mathrm{H}_{2} \mathrm{O}_{2}$ occurs mainly at the surface of $\mathrm{ROXN}_{673}$ (heterogeneous reaction). A similar trend to that discussed for phenol and TOC conversions is also observed regarding the efficiency of $\mathrm{H}_{2} \mathrm{O}_{2}$ consumption. As observed, the ratio $\mathrm{X}_{\mathrm{TOC}} / \mathrm{X}_{\mathrm{H}_{2} \mathrm{O}_{2}}$ decreases from the first to the second cycle, being kept nearly constant afterward (cf. Figure 7). Overall, at the end of the three CWPO cycles performed with consecutive reuse of $\mathrm{ROXN}_{673}, 33 \%$ of the initial iron content (cf. Table 2) remains in the spent catalyst. Additional studies are required to better understand the effect of these apparently more strongly attached iron species on the stability of ROXN 673 in CWPO.

\section{Materials and Methods}

\subsection{Reactants}

Phenol (99 wt \%), hydroquinone (99 wt \%), resorcinol (99 wt \%), titanium (IV) oxysulfate (15 wt \% in dilute sulfuric acid), sodium hydroxide ( $97 \mathrm{wt} \%$ ) and hydrochloric acid (37 wt \%) were obtained from Sigma-Aldrich (Steinhein, Germany). Hydrogen peroxide (30 wt \%), $p$-benzoquinone (99.5 wt \%) and catechol (98 wt \%) were purchased from Honeywell Fluka (Charlotte, NC, USA). Sodium chloride (99.5 wt \%) was purchased from Merck Millipore (Darmstadt, Germany). Sulfuric acid (95 wt \%) and methanol (99.9 wt \%), used for high-performance liquid chromatography (HPLC), were obtained from VWR Prolabo Chemicals (Bruchsal, Germany). All the solutions were prepared with distilled water. 


\subsection{Activated Carbons}

Five commercial ACs were considered in this work, four samples from Cabot Norit (Boston, MA, USA): (i) ROX 0.8 (ROX); (ii) RX 3-Extra (RX3); (iii) C-Gran (C-GRAN); (iv) PK 0.25-1 (PK0.25); and one sample from DEGUSSA (Hanau, Germany): v) HYDRAFFIN AS 12/450 (AS12). Moreover, ROX was modified by thermal treatments performed under different atmospheres and at different temperatures. ROXN was obtained after annealing under nitrogen flow $\left(100 \mathrm{~cm}^{3} \mathrm{~min}^{-1}\right)$, at 573 and $873 \mathrm{~K}$, for $60 \mathrm{~min}$ at each temperature and then at $1073 \mathrm{~K}$ for $240 \mathrm{~min}$, defining a heating ramp of $2 \mathrm{~K} \mathrm{~min}^{-1}$. ROXN was then thermally activated under oxidative atmosphere (airflow $=100 \mathrm{~cm}^{3} \mathrm{~min}^{-1}$ ) for $60 \mathrm{~min}$ at different temperatures, ranging from 473 to $673 \mathrm{~K}$, the resulting materials being labeled as ROXN $\mathrm{N}_{X X}$, where $X X$ denotes the temperature employed (in $\mathrm{K}$ ).

\subsection{Characterization Techniques}

The $\mathrm{pH}$ at the point of zero charge $\left(\mathrm{pH}_{\mathrm{PZC}}\right)$ of the samples was determined by $\mathrm{pH}$ drift tests, adapting the procedure previously described [29]. For that purpose, $50 \mathrm{~mL}$ solutions of $\mathrm{NaCl}$ $\left(0.01 \mathrm{~mol} \mathrm{~L}^{-1}\right)$ with five different initial $\mathrm{pH}$, adjusted by the addition of $\mathrm{HCl}$ or $\mathrm{NaOH}$ solutions, were prepared in closed Erlenmeyer flasks. A total of $0.15 \mathrm{~g}$ of AC sample was added to each flask, and the final $\mathrm{pH}$ was measured after $24 \mathrm{~h}$ under stirring at room temperature. The $\mathrm{pH}_{\mathrm{PZC}}$ of each $\mathrm{AC}$ sample was determined when the curve $\mathrm{pH}_{\text {final }}$ vs. $\mathrm{pH}_{\text {initial }}$ crosses the line $\mathrm{pH}_{\text {final }}=\mathrm{pH}_{\text {initial }}$.

Following IUPAC guidelines [30], the textural properties were determined from the analysis of $\mathrm{N}_{2}$ adsorption-desorption isotherms at $77 \mathrm{~K}$, as previously described [29].

Temperature programmed desorption (TPD) analysis was performed in a fully automated AMI-300 Catalyst Characterization Instrument (Altamira Instruments, Pittsburgh, PA, USA), equipped with a quadrupole mass spectrometer (Dymaxion, Ametek, Berwyn, PA, USA), as described elsewhere [19,22]. Briefly, the AC sample $(0.10 \mathrm{~g})$ was placed in a U-shaped quartz tube inside an electrical furnace and heated at $5 \mathrm{~K} \mathrm{~min}^{-1}$ up to $1073 \mathrm{~K}$ using a constant flow rate of helium $\left(25 \mathrm{~cm}^{3} \mathrm{~min}^{-1}\right)$. The mass signals $\mathrm{m} / \mathrm{z}=28$ and 44 were monitored during the thermal analysis, the corresponding TPD spectra being obtained. $\mathrm{CO}$ and $\mathrm{CO}_{2}$ were calibrated at the end of each analysis with the respective gases.

The total iron content of the ACs (as impurities resulting from the industrial synthesis procedures) was determined by atomic absorption analysis of the solutions resulting from acidic digestion of the samples, as previously described [13]. All determinations were performed in duplicate. The standard deviation of iron content determination never exceeded $0.03 \mathrm{wt} \%$.

\subsection{Adsorption and CWPO Runs}

All experiments were performed in a round-bottomed glass reactor (nominal volume $=250 \mathrm{~mL}$ ), equipped with a stirring bar, coupled to a condenser and immersed in a water bath with controlled temperature. Upon stabilization at the desired temperature, the solution $\mathrm{pH}$ was adjusted to 3.5 through a $1.0 \mathrm{~mol} \mathrm{~L}^{-1} \mathrm{HCl}$ solution, since this process typically operates better under $\mathrm{pH}$ values in the range 2.5-4.0, as previously found in other works [31,32]. The experiments were conducted during $24 \mathrm{~h}$, with $T=353 \mathrm{~K}, \mathrm{pH}=3.5,50 \mathrm{~mL}$ of a phenol solution $\left(4.5 \mathrm{~g} \mathrm{~L}^{-1}\right)$, [adsorbent/catalyst] $=2.5 \mathrm{~g} \mathrm{~L}^{-1}$, and, in CWPO runs, with $\left[\mathrm{H}_{2} \mathrm{O}_{2}\right]_{0}=25 \mathrm{~g} \mathrm{~L}^{-1}$ (i.e., the stoichiometric amount needed to mineralize phenol completely).

In adsorption runs, the adsorbent was added after $\mathrm{pH}$ adjustment to reach the desired load in solution, that instant being defined as $t_{0}=0 \mathrm{~min}$. In CWPO runs, $\mathrm{H}_{2} \mathrm{O}_{2}$ was supplied after catalyst addition, that moment being considered as $t_{0}=0 \mathrm{~min}$. Non-catalytic oxidation promoted by $\mathrm{H}_{2} \mathrm{O}_{2}$ was evaluated in experiments performed in the absence of a catalyst. All experiments were performed in duplicate; the standard deviation of phenol determination never exceeded $2 \%$. 


\subsection{Analytical Methods}

The concentrations of phenol and other aromatic compounds were determined by high-performance liquid chromatography, as previously described [13]. Specifically, resorcinol, p-benzoquinone, phenol, catechol and hydroquinone detection was performed at 210, 247, 270, 277 and $290 \mathrm{~nm}$, respectively.

Iron leaching was determined by atomic absorption (Spectra 220, Varian, Inc., Palo Alto, CA, USA). The concentration of $\mathrm{H}_{2} \mathrm{O}_{2}$ was determined by a colorimetric method with titanium oxysulfate, as previously described [15]. Total organic carbon (TOC) was analyzed in a Shimadzu TOC-5000A apparatus (Kyoto, Japan).

\section{Conclusions}

The performance of the apparently most active catalysts (PK0.25 and AS12) was primarily attributed to the impurities of iron present in their carbon structure that leach into the solution (homogeneous reaction). On the contrary, ROX was better suited for CWPO due to the lower iron leaching. Thermal modification of ROX through annealing under inert atmosphere and activation under an oxidative atmosphere at $673 \mathrm{~K}\left(\mathrm{ROXN}_{673}\right)$ increased its activity significantly for the CWPO of highly concentrated phenol solutions, leading to a high pollutant mass removal of $1656 \mathrm{mg} \mathrm{g}^{-1}$ after $24 \mathrm{~h}$. This enhanced performance was mainly ascribed to better accessibility to iron impurities at the surface of the catalyst (heterogeneous reaction), which act as active sites for the decomposition of $\mathrm{H}_{2} \mathrm{O}_{2}$. Reusability studies confirmed the high activity of $\mathrm{ROXN}_{673}$ in CWPO, as significant degradation (ca. $70 \%$ ) and mineralization (ca. $40 \%$ ) of phenol were still observed in the third CWPO run performed with consecutive catalyst reuse.

Author Contributions: Conceptualization, H.T.G., J.L.F. and A.M.T.S.; formal analysis, M.T.P. and R.S.R.; funding acquisition, H.T.G., J.L.F. and A.M.T.S.; investigation, M.T.P.; methodology, R.S.R.; project administration, H.T.G., J.L.F. and A.M.T.S.; supervision, H.T.G., J.L.F. and A.M.T.S.; writing-original draft, M.T.P.; writing-review and editing, R.S.R., H.T.G., J.L.F. and A.M.T.S. All authors have read and agreed to the published version of the manuscript.

Funding: This work was financially supported by project NORTE-01-0145-FEDER-031049 (InSpeCt-PTDC/EAM-AMB/31049/2017) funded by FEDER funds through NORTE 2020-Programa Operacional Regional do NORTE and by national funds (PIDDAC) through FCT/MCTES. We would also like to thank the scientific collaboration under Base Fundings-UIDP/50020/2020 of the Associate Laboratory LSRE-LCM and UIDB/00690/2020 of the Centro de Investigação de Montanha (CIMO)—funded by national funds through FCT/MCTES (PIDDAC).

Conflicts of Interest: The authors declare no conflict of interest. The funders had no role in the design of the study; in the collection, analyses or interpretation of data; in the writing of the manuscript or in the decision to publish the results.

\section{References}

1. Rey, A.; Zazo, J.; Casas, J.; Bahamonde, A.; Rodriguez, J. Influence of the structural and surface characteristics of activated carbon on the catalytic decomposition of hydrogen peroxide. Appl. Catal. A Gen. 2011, 402, 146-155. [CrossRef]

2. Rey, A.; Faraldos, M.; Casas, J.; Zazo, J.; Bahamonde, A.; Rodríguez, J. Catalytic wet peroxide oxidation of phenol over Fe/AC catalysts: Influence of iron precursor and activated carbon surface. Appl. Catal. B Environ. 2009, 86, 69-77. [CrossRef]

3. Lücking, F.; Köser, H.; Jank, M.; Ritter, A. Iron powder, graphite and activated carbon as catalysts for the oxidation of 4-chlorophenol with hydrogen peroxide in aqueous solution. Water Res. 1998, 32, 2607-2614. [CrossRef]

4. Khalil, L.B.; Girgis, B.S.; Tawfik, T.A.M. Decomposition of $\mathrm{H}_{2} \mathrm{O}_{2}$ on activated carbon obtained from olive stones. J. Chem. Technol. Biotechnol. 2001, 76, 1132-1140. [CrossRef]

5. Serp, P.; Figueiredo, J.L. Carbon Materials for Catalysis; John Wiley \& Sons, Inc.: Hoboken, NJ, USA, 2009.

6. Figueiredo, J.L. Functionalization of porous carbons for catalytic applications. J. Mater. Chem. A 2013, 1, 9351-9364. [CrossRef] 
7. Ribeiro, R.S.; Silva, A.M.; Figueiredo, J.; Faria, J.; Gomes, H.T. Catalytic wet peroxide oxidation: A route towards the application of hybrid magnetic carbon nanocomposites for the degradation of organic pollutants. A review. Appl. Catal. B Environ. 2016, 187, 428-460. [CrossRef]

8. Munoz, M.; de Pedro, Z.M.; Casas, J.A.; Rodriguez, J.J. Preparation of magnetite-based catalysts and their application in heterogeneous Fenton oxidation-A review. Appl. Catal. B 2015, 176-177, 249-265. [CrossRef]

9. Gogate, P.R.; Pandit, A.B. A review of imperative technologies for wastewater treatment I: Oxidation technologies at ambient conditions. Adv. Environ. Res. 2004, 8, 501-551. [CrossRef]

10. Navalón, S.; Alvaro, M.; Garcia, H. Heterogeneous Fenton catalysts based on clays, silicas and zeolites. Appl. Catal. B Environ. 2010, 99, 1-26. [CrossRef]

11. Dhaouadi, A.; Adhoum, N. Heterogeneous catalytic wet peroxide oxidation of paraquat in the presence of modified activated carbon. Appl. Catal. B Environ. 2010, 97, 227-235. [CrossRef]

12. Domínguez, C.; Ocón, P.; Quintanilla, A.; Casas, J.; Rodriguez, J. Graphite and carbon black materials as catalysts for wet peroxide oxidation. Appl. Catal. B Environ. 2014, 144, 599-606. [CrossRef]

13. Pinho, M.T.; Gomes, H.T.; Ribeiro, R.S.; Faria, J.L.; Silva, A.M.T. Carbon nanotubes as catalysts for catalytic wet peroxide oxidation of highly concentrated phenol solutions: Towards process intensification. Appl. Catal. B Environ. 2015, 165, 706-714. [CrossRef]

14. Domínguez, C.; Ocón, P.; Quintanilla, A.; Casas, J.; Rodriguez, J. Highly efficient application of activated carbon as catalyst for wet peroxide oxidation. Appl. Catal. B Environ. 2013, 663-670. [CrossRef]

15. Ribeiro, R.S.; Silva, A.M.; Pastrana-Martínez, L.M.; Figueiredo, J.; Faria, J.; Gomes, H.T. Graphene-based materials for the catalytic wet peroxide oxidation of highly concentrated 4-nitrophenol solutions. Catal. Today 2015, 249, 204-212. [CrossRef]

16. Ribeiro, R.S.; Rodrigues, R.O.; Silva, A.M.; Tavares, P.B.; Carvalho, A.M.; Figueiredo, J.; Faria, J.; Gomes, H.T. Hybrid magnetic graphitic nanocomposites towards catalytic wet peroxide oxidation of the liquid effluent from a mechanical biological treatment plant for municipal solid waste. Appl. Catal. B Environ. 2017, 219, 645-657. [CrossRef]

17. Gomes, H.T.; Miranda, S.M.; Sampaio, M.J.; Silva, A.M.; Faria, J.L. Activated carbons treated with sulphuric acid: Catalysts for catalytic wet peroxide oxidation. Catal. Today 2010, 151, 153-158. [CrossRef]

18. Figueiredo, J.L.; Pereira, M.F.R. The role of surface chemistry in catalysis with carbons. Catal. Today 2010, 150, 2-7. [CrossRef]

19. Figueiredo, J.; Pereira, M.; Freitas, M.; Órfão, J. Modification of the surface chemistry of activated carbons. Carbon 1999, 37, 1379-1389. [CrossRef]

20. Ribeiro, R.S.; Silva, A.M.; Pinho, M.T.; Figueiredo, J.L.; Faria, J.L.; Gomes, H.T. Development of glycerol-based metal-free carbon materials for environmental catalytic applications. Catal. Today 2015, 240, 61-66. [CrossRef]

21. Martínez, F.; Pariente, M.I.; Botas, J.A.; Melero, J.A.; Rubalcaba, A. Influence of preoxidizing treatments on the preparation of iron-containing activated carbons for catalytic wet peroxide oxidation of phenol. J. Chem. Technol. Biotechnol. 2012, 87, 880-886. [CrossRef]

22. Figueiredo, J.L.; Pereira, M.F.R.; Freitas, M.M.A.; Órfão, J.J.M. Characterization of Active Sites on Carbon Catalysts. Ind. Eng. Chem. Res. 2007, 46, 4110-4115. [CrossRef]

23. Vieira, O.; Ribeiro, R.S.; Pedrosa, M.; Lado Ribeiro, A.R.; Silva, A.M.T. Nitrogen-doped reduced graphene oxide-PVDF nanocomposite membrane for persulfate activation and degradation of water organic micropollutants. Chem. Eng. J. 2020, 402, 126117. [CrossRef]

24. Moreno-Castilla, C.; Rivera-Utrilla, J.; López-Ramón, M.V.; Carrasco-Marin, F. Adsorption of some substituted phenols on activated carbons from a bituminous coal. Carbon 1995, 33, 845-851. [CrossRef]

25. Terzyk, A.P. Further insights into the role of carbon surface functionalities in the mechanism of phenol adsorption. J. Colloid Interface Sci. 2003, 268, 301-329. [CrossRef]

26. Martin-Martinez, M.; Ribeiro, R.S.; Machado, B.F.; Serp, P.; Morales-Torres, S.; Silva, A.M.; Figueiredo, J.; Faria, J.; Gomes, H.T. Role of Nitrogen Doping on the Performance of Carbon Nanotube Catalysts: A Catalytic Wet Peroxide Oxidation Application. ChemCatChem 2016, 8, 2068-2078. [CrossRef]

27. Munoz, M.; Domínguez, C.M.; De Pedro, Z.; Quintanilla, A.; Casas, J.; Rodriguez, J.J.; Munoz, M. Degradation of imidazolium-based ionic liquids by catalytic wet peroxide oxidation with carbon and magnetic iron catalysts. J. Chem. Technol. Biotechnol. 2016, 91, 2882-2887. [CrossRef]

28. Sheldon, R.A.; Wallau, M.; Arends, I.W.C.E.; Schuchardt, U. Heterogeneous Catalysts for Liquid-Phase Oxidations: Philosophers' Stones or Trojan Horses? Acc. Chem. Res. 1998, 31, 485-493. [CrossRef] 
29. Ribeiro, R.S.; Frontistis, Z.; Mantzavinos, D.; Venieri, D.; Antonopoulou, M.; Konstantinou, I.K.; Silva, A.M.; Faria, J.L.; Gomes, H.T. Magnetic carbon xerogels for the catalytic wet peroxide oxidation of sulfamethoxazole in environmentally relevant water matrices. Appl. Catal. B Environ. 2016, 199, 170-186. [CrossRef]

30. Thommes, M.; Kaneko, K.; Neimark, A.V.; Olivier, J.P.; Rodriguez-Reinoso, F.; Rouquerol, J.; Sing, K.S. Physisorption of gases, with special reference to the evaluation of surface area and pore size distribution (IUPAC Technical Report). Pure Appl. Chem. 2015, 87, 1051-1069. [CrossRef]

31. Barrault, J.; Tatibouet, J.-M.; Papayannakos, N. Catalytic wet peroxide oxidation of phenol over pillared clays containing iron or copper species. Comptes Rendus de l'Académie des Sciences-Ser. IIC-Chem. 2000, 3, 777-783. [CrossRef]

32. Pouran, S.R.; Raman, A.A.A.; Daud, W.M.A.W. Review on the application of modified iron oxides as heterogeneous catalysts in Fenton reactions. J. Clean. Prod. 2014, 64, 24-35. [CrossRef]

Publisher's Note: MDPI stays neutral with regard to jurisdictional claims in published maps and institutional affiliations.

(C) 2020 by the authors. Licensee MDPI, Basel, Switzerland. This article is an open access article distributed under the terms and conditions of the Creative Commons Attribution (CC BY) license (http://creativecommons.org/licenses/by/4.0/). 